\title{
Executive Function
}

National Cancer Institute

\section{Source}

National Cancer Institute. Executive Function. NCI Thesaurus. Code C88419.

A set of mental processes that controls and manages the cognitive functions. 